WellBeing International

WBI Studies Repository

2002

\title{
Cognitive and Communicative Abilities of Grey Parrots
}

Irene M. Pepperberg

Massachusetts Institute of Technology

Follow this and additional works at: https://www.wellbeingintlstudiesrepository.org/acwp_asie

Part of the Animal Studies Commons, Comparative Psychology Commons, and the Other Animal Sciences Commons

\section{Recommended Citation}

Pepperberg, I. M. (2002). Cognitive and communicative abilities of grey parrots. Current Directions in Psychological Science, 11(3), 83-87.

This material is brought to you for free and open access by WellBeing International. It has been accepted for inclusion by an authorized administrator of the WBI Studies Repository. For more information, please contact wbisr-info@wellbeingintl.org.

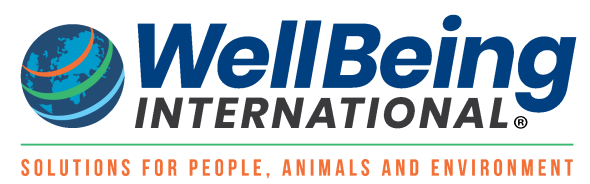




\title{
Cognitive and Communicative Abilities of Grey Parrots
}

\author{
Irene M. Pepperberg \\ Massachusetts Institute of Technology \\ Brandeis University
}

KEYWORDS

parrot cognition, parrot communication, vocal learning, social learning

\begin{abstract}
Grey parrots (Psittacus erithacus) solve various cognitive tasks and acquire and use English speech in ways that often resemble those of very young children. Given that the psittacine brain is organized very differently from that of mammals, these results have intriguing implications for the study and evolution of vocal learning, communication, and cognition.
\end{abstract}

For 25 years, I have taught Grey parrots meaningful use of English speech (e.g., to label objects, colors, shapes, categories, quantities, and absence). Using this code, my oldest subject, Alex, exhibits cognitive capacities comparable to those of marine mammals, apes, and sometimes 4-year-old children (Pepperberg, 1999). Thus, his abilities are inferred not from operant tasks common in animal research, but from vocal responses to vocal questions; that is, he demonstrates intriguing communicative parallels with young humans, despite his evolutionary distance. I doubt I taught Alex and other parrots these abilities de novo; their achievements likely derive from existent cognitive and neurological architectures. My research therefore uses interspecies communication as an investigative tool to unveil avian communicative capacities and an avian perspective on the evolution of communication.

\section{SIGNIFICANCE OF INTERSPECIES COMMUNICATION}

Parrots' vocal plasticity enables direct interspecies communication (Pepperberg, 1999). But why study their ability to use English rather than their natural system? The answer involves their existent cognitive architecture. I believe parrots acquire those elements of human communication that can be mapped or adapted to their own code. By observing what is or is not acquired, I uncover these elements and interpret the avian system. I believe parrots could not learn aspects of reference (e.g., labels for particular colors, object classes such as "apple") unless their natural code had such referentiality. Although this manner of determining nonhuman referentiality is inferential, direct determination also has difficulties (see 
Cheney \& Seyfarth, 1992). Moreover, pushing avian systems to see what input engenders exceptional learning (i.e., learning that does not necessarily occur during normal development-in this case, acquiring another species' code) further elucidates learning processes: Because richer input is needed for a bird to learn another species' code (allospecific acquisition) than for it to learn its own species' code (conspecific learning) (Pepperberg, 1999), this line of research can show how and whether "nurture" modifies "nature" (e.g., alters innate predispositions toward conspecific learning), and thus uncover additional mechanisms for, and the extent of, communicative learning. Again, these mechanisms are likely part of existent cognitive architectures, not taught de novo.

Interspecies communication also has practical applications. It is a tool that (a) directly states question content-animals need not determine both a query's aim and the answer via trial and error; (b) exploits research showing that social animals may respond more readily and accurately within ecologically valid social contexts than in other situations; (c) facilitates data comparisons among species, including humans; (d) allows rigorous testing of the acquired communication code that avoids expectation cuing (i.e., subjects must choose responses from their entire repertoire; they cannot expect the answer to come from a subset of choices relevant only to the topic under question); and, most important, (e) is also an open, arbitrary, creative code with enormous signal variety, enabling animals to respond in novel, possibly innovative ways that demonstrate greater competence than operant paradigms' required responses, and ( $f$ ) thereby allows examination of the nature and extent of information animals perceive. Interspecies communication facilely demonstrates nonhumans' inherent capacities and may enable complex learning (Pepperberg, 1999).

\section{HOW GREYS LEARN: PARALLELS WITH HUMANS}

My Greys' learning sometimes parallels human processes, suggesting insights into how acquisition of complex communication may have evolved. Referential, contextually applicable (functional), and socially rich input allows parrots, like young children, to acquire communication skills effectively (Pepperberg, 1999). Reference is an utterance's meaning - the relationship between labels and objects to which they refer. Thus, in my research, utterances have reference because the birds are rewarded by being given the objects they label. Context (function) involves the situation in which an utterance is used and effects of its use. The utterances also are functional because they initially are used-and responded to-as requests; this initial use of labels as requests gives birds a reason to learn sounds constituting English labels. Social interaction, which is integral to the research, accents environmental components, emphasizes common attributes-and possible underlying rules-of diverse actions, and allows continuous adjustment of input to learners' levels. Interaction engages subjects directly, provides contextual explanations for actions, and demonstrates actions' consequences. In this section, I describe the primary training technique, then experiments my students and I have conducted to determine which input elements are necessary and sufficient to engender learning.

\section{Model/Rival Training}

My model/rival (M/R) training system (background in Pepperberg, 1999) uses three-way social interactions among two humans and a parrot to demonstrate targeted vocal behavior. The parrot observes two humans handling one or more objects, then watches the humans interact: The trainer presents, and queries the human model about, the item (or multiple items) (e.g., "What's here?" "What color?") and praises the model and gives him or her the object (or objects) as a referential reward for answers that are correct. Incorrect responses (like the bird may make) are punished by scolding and temporarily removing the item (or items) from sight. Thus, the second human is a model for the parrot's responses, is its rival for the trainer's attention, and also illustrates the consequences of making an error: The model is asked to try again or talk more clearly if the response was (deliberately) incorrect or garbled, 
so the method demonstrates corrective feedback. The bird is also queried and initially rewarded for approximations to "correct" responses. As training progresses, the criteria for what constitutes a correct response become increasingly strict; thus, training is adjusted to the parrot's level.

Unlike other laboratories' M/R procedures (see Pepperberg, 1999), ours interchanges the roles of trainer and model, and includes the parrot in interactions, to emphasize that one being is not always the questioner and the other the respondent, and that the procedure can effect environmental change. Role reversal also counteracts an earlier methodological problem: Birds whose trainers always maintained their respective roles responded only to the human questioner. Our birds, however, respond to, interact with, and learn from all humans.

M/R training exclusively uses intrinsic reinforcers: To ensure the closest possible correlations of labels or concepts to be learned with their appropriate referents, we reward a bird for uttering " $X$ " by giving the bird $X$ (i.e., the object to which the label or concept refers). Earlier unsuccessful programs for teaching birds to communicate with humans used extrinsic rewards (Pepperberg, 1999): The reward was one food that neither related to, nor varied with, the label or concept being taught. Use of extrinsic rewards delays label and concept acquisition because it confounds the label of the targeted exemplar or concept with that of the food. My birds never receive extrinsic rewards.

Because Alex sometimes fails to focus on targeted objects, we trained him to say, "I want X" (i.e., to separate labeling and requesting; see Pepperberg, 1999), in order to request the reward he wants. That is, if he identifies something correctly, his reward can be the right to request something more desirable than what he has identified. This procedure provides flexibility but maintains referentiality. Thus, to receive $X$ after identifying $Y$, Alex must state, "I want $X$," and trainers will not comply until the original identification task involving $Y$ is completed. His labels therefore are true identifiers, not merely emotional requests. Adding "want" provides additional advantages: First, trainers can distinguish incorrect labeling from appeals for other items, particularly during testing, when birds unable to use "want" might misidentify objects not because they do not know the correct label but because they are asking for treats, and their performance might reflect a lack of accuracy unrelated to their actual competence. Second, birds may demonstrate low-level intentionality: Alex rarely accepts substitutes when requesting $X$, and continues his demands (see Pepperberg, 1999), thus showing that he truly intends to obtain X when he says "want X."

\section{Eliminating Aspects of Input}

$M / R$ training with Alex successfully demonstrated that reference, functionality, and social interaction during training enabled label and concept acquisition, but not which or how many of these elements were necessary, sufficient, or both. What would happen if some of these elements were lacking from the input? Answering that question required training and testing additional parrots, because Alex might cease learning after a change in training merely because there was a change, not necessarily because of the type of change. With 3 new naive Greys-Kyaaro, Alo, and Griffin-students and I performed seven sets of experiments (see Pepperberg, 1999; Pepperberg, Sandefer, Noel, \& Ellsworth, 2000) to test the relative importance of reference, functionality, and social interaction in training.

In the first set of experiments, we compared simultaneous exposure of Alo and Kyaaro to three input conditions: In Condition I, they heard audiotapes of Alex's sessions, so that the input was nonreferential, not contextually applicable, and noninteractive; in Condition II, they were presented videotapes of Alex's sessions, so that the input was referential, minimally contextually applicable, and noninteractive; and in Condition III, they received standard M/R training. In Conditions I and II, the birds experienced the tapes in social isolation. Condition I paralleled early allospecific song-acquisition studies (e.g., Marler, 1970); Condition II involved still-unresolved issues about avian vision and video (e.g., whether the flickering of 
the cathode ray tube of the television and the lack of ultraviolet, which birds can see, affect their ability to attend to video or recognize video as representing reality; see Ikebuchi \& Okanoya, 1999). We counterbalanced labels across birds, matching training time across sessions. Each bird received training in all three conditions, but some different labels were trained under different conditions for the 2 birds, and some labels were trained under the same conditions.

The second through fifth experiments examined video exposure in more detail. The second and third experiments investigated the possible effects a co-viewer might have on learning from video. Because interactive co-viewers can increase young children's learning from video (Rice, Huston, Truglio, \& Wright, 1990), in the second experiment a co-viewer provided social approbation for viewing and pointed to the screen while making comments like "Look what Alex has!" but did not repeat targeted labels, ask questions, or relate content to other training. Birds' attempts to utter a label garnered only vocal praise. Social interaction was limited; referentiality and functionality were the same as in earlier videotape sessions. Also, because the extent of a co-viewer's interaction might affect children's learning from video, in the third experiment our co-viewer uttered targeted labels and asked questions. Because lack of reward might deter video learning, in the fourth experiment a socially isolated parrot watched videos while a student in another room monitored its utterances through headphones and could deliver rewards remotely. In the fifth experiment, we used live video from Alex's sessions, because in the other experiments birds might have habituated to the single videotape used per label (even though each tape depicted many different responses and interactions among Alex and trainers). We are now replicating video studies with a liquid crystal monitor to see whether it is the flickering of the standard cathode ray tube that affects learning (Ikebuchi \& Okanoya, 1999) rather than any of our experimental manipulations.

The sixth experiment examined the role of joint focus on the part of the bird and trainer, because research showed that if adult-child duos failed to focus jointly on objects being labeled, the labels were not acquired (e.g., Baldwin, 1995). In this experiment, a single trainer faced away from the bird (who was within reach of, e.g., a key) and talked about the object, emphasizing its label ("Look, a shiny key!" "Do you want key?" etc.; i.e., the trainer used sentences that framed the label, allowing for repeated use of the label without causing habituation; Pepperberg, 1999), but had no visual or physical contact with parrot or object; a bird's attempts to utter the targeted label would receive only vocal praise, so that some functionality and considerable social interaction were eliminated.

Parrots failed to acquire referential use of targeted labels in any of these non-M/R conditions, but succeeded in M/R sessions that we conducted concurrently on other labels (Pepperberg, 1999). These results indicated the importance of including reference, demonstrations of contextual use (functionality), and social interaction in training if parrots are to communicate with humans rather than mimic speech. Nevertheless, at least one other condition remained to be tested.

Thus, in the seventh experiment we eliminated some interactive aspects of modeling by having a single student label objects, query the bird, jointly attend to objects, and therefore interact fully with the bird and the objects. Griffin did not utter labels in 50 such sessions, but clearly produced labels after two or three subsequent $M / R$ sessions. We suspected that Griffin had in fact acquired labels during the previous sessions, but did not use them until he observed their use modeled. (Note that birds that were switched to $\mathrm{M} / \mathrm{R}$ training after 50 video sessions needed about 20 sessions before producing labels.)

\section{Mutual Exclusivity: Studying Subtle Changes in Input}

Our parrots' learning processes may also parallel young children's very early label acquisition in showing evidence for mutual exclusivity, the notion that each object has one, and only one, label (Liittschwager \& Markman, 1994; Pepperberg \& Wilcox, 2000). Along with the whole-object assumption (that a label refers 
to an entire object, not some feature of it), mutual exclusivity supposedly guides children's initial label acquisition (e.g., Liittschwager \& Markman, 1994). Mutual exclusivity may also help children interpret novel words as feature labels (i.e., overcome the whole-object assumption), but very young children may find second labels for items initially more difficult to acquire than the first labels because second labels are viewed as alternatives (Liittschwager \& Markman, 1994). Input, however, affects mutual exclusivity: Children (Gottfried \& Tonks, 1996), and parrots like Alex, who receive input indicating that more than one label can apply to an object (e.g., that a color label is an additional, not an alternative, label, as in "Here's a key; it's a green key") generally accept multiple labels for items and form hierarchical relations. Thus, when shown a wooden block, Alex is able to answer "What color?" "What shape?" "What matter?" and "What toy?" (Pepperberg, 1999). Parrots such as Griffin, given colors or shapes as alternative labels for a particular object (e.g., "Here's a key" and later "It's green"), however, have difficulty learning to use these modifiers for previously labeled items. Griffin, for example, after learning to label a particular type of object as "wool" and learning color from swatches, initially would persist in replying "wool" when shown the object and asked, "What color?" Similarly, he had difficulty learning the object label "cup" after learning to label the color of various plastic cups, and responded with color labels when shown a cup and asked, "What toy?" Thus, even small input changes (e.g., "It's a green key" vs. "It's green") affect label acquisition as much for parrots as for young children.

\section{Combinatory Learning}

Primarily on the basis of behavioral data, researchers (e.g., Johnson-Pynn, Fragaszy, Hirsh, Brakke, \& Greenfield, 1999) argue that a common neural substrate initially underlies young children's simultaneous development of the ability to combine their single labels into phrases and the ability to combine multiple objects into ordered groups (e.g., stacking cups by size), that a homologous substrate in great apes allows similar, limited, parallel development, and that such data imply a shared evolutionary history for communicative and physical behavior. But Griffin showed comparable limited, simultaneous combinatorial development of three-item and three-label combinations (Pepperberg \& Shive, 2001): As percentages of all physical and vocal actions, respectively, his combinations of physical objects and vocal combinations of labels were roughly equal; despite months of training on labels, his vocal three-label combinations emerged only after he began to initiate three-object combinations; and his vocal combinations were generally not ones that had been trained. In contrast to primates, he performed his physical combinations with his beak, not feet. Moreover, unlike the Cebus monkeys that were trained by Johnson-Pynn et al. (1999) to perform manual combinations, but like the chimpanzees these researchers also studied, Griffin was not trained on the physical tasks. In addition, although we trained him on three-label combinations to demonstrate that such combinations were acceptable and possible, we limited this training (i.e., he was trained to identify only two- and five-corner wood and paper items); we could then see if spontaneous manipulative behavior developed in parallel with spontaneous vocal complexity (i.e., production of untrained three-label combinations).

Although Griffin's behavior-or that of our most advanced subject, Alex (e.g., Pepperberg, 1999)—is equivalent neither to human language nor 2- to 3-year-old humans' combinatory behavior, we suggest that our Greys' behavior patterns match some behavior patterns of nonhuman primates, that parallel combinatory development is not limited to primates, and that a particular mammalian brain structure is not uniquely responsible for such behavior. Neurological substrates responsible for these behavior patterns are likely analogous across species, arising independently under similar evolutionary pressures (but see Medina \& Reiner, 2000), and searches for and arguments concerning such substrates and common behavior should not be restricted to primates. 


\section{PARALLEL EVOLUTION OF AVIAN AND MAMMALIAN ABILITIES?}

Although human behavior and animal behavior are not isomorphic, researchers must examine many species for information on evolutionary pressures that helped shape existent systems (Pepperberg, 1999). Such pressures were exerted not only on primates, so it is not surprising that birds have analogous complex communication systems that are based in analogous neural architectures. Moreover, complex communicative systems either require or likely coevolve with complex cognition: Although communication is functionally social, its complexity is based on the complexity of information communicated, processed, and received; thus, the types of contingencies that influenced the evolution of intelligence (social, ecological, etc.) also likely shaped the evolution of complex communication. A common hypothesis is that intelligence is a correlate of primates' complicated social systems and long lives, that is, the outcome of selection processes favoring animals that flexibly transfer skills across distinct domains (Rozin, 1976) and that remember and act upon knowledge of detailed social relations among group members (Humphrey, 1976). The same evolutionary pressures might have driven parrot cognition and vocal behavior: Long-lived birds with complex social systems not unlike those of primates could use abilities honed for social gains to direct information processing and vocal learning capacities. Given needs for categorical classes (e.g., to distinguish neutral stimuli from predators), abilities to recognize and remember environmental regularities and adapt to unpredictable environmental changes over extensive lifetimes, and a primarily vocal communication system, parrots' capacities are not surprising. Whether avian and human abilities evolved convergently-that is, whether similar adaptive responses independently evolved in association with similar environmental pressures-is unclear, but a common core of skills likely underlies the complex cognitive and communicative behavior found across species, even if the species differ in their specific skills.

Questions now remain about such skills: Can birds that, for example, understand same-different, biggersmaller, and number concepts also learn to respond to a situation by taking into account the perspective of another individual, to engage in deceptive conversations, or to expand their limited syntactic capacities? Even without such additional demonstrations, researchers must examine their negative biases about avian abilities: Only by looking for commonalities across species can we develop successful theories about behavioral elements essential to, and the evolutionary pressures that have shaped, complex capacities (Pepperberg, 1999).

\section{Acknowledgments}

Writing this article was supported by MIT's Media Lab; research was supported by National Science Foundation Grant IBN 96-03803, REU supplements, the John Simon Guggenheim Foundation, Kenneth A. Scott Charitable Trust, The Pet Care Trust, University of Arizona Undergraduate Biology Research Program, and Alex Foundation donors.

\section{References}

Baldwin, D.A. (1995). Understanding the link between joint attention and language. In C. Moore \& P.J. Dunham (Eds.), Joint attention (pp. 131-158). Hillsdale, NJ: Erlbaum.

Cheney, D.L., \& Seyfarth, R.M. (1992). Precis of 'How monkeys see the world.' Behavioral and Brain Sciences, 15, 135-182. 
Gottfried, G.M., \& Tonks, J.M. (1996). Specifying the relation between novel and known: Input affects the acquisition of novel color terms. Child Development, 67, 850-866.

Humphrey, N.K. (1976). The social function of intellect. In P.P.G. Bateson \& R.A. Hinde (Eds.), Growing points in ethology (pp. 303-317). Cambridge, England: Cambridge University Press.

Ikebuchi, M., \& Okanoya, K. (1999). Male zebra finches and Bengalese finches emit directed songs to the video images of conspecific females projected onto a TFT display. Zoological Science, 16, 63-70.

Johnson-Pynn, J., Fragaszy, D.M., Hirsh, E.M., Brakke, K.E., \& Greenfield, P.M. (1999). Strategies used to combine seriated cups by chimpanzees (Pan troglodytes), bonobos (Pan paniscus), and capuchins (Cebus apella). Journal of Comparative Psychology, 113, 137-148.

Liittschwager, J.C., \& Markman, E.M. (1994). Sixteen-and 24-month olds' use of mutual exclusivity as a default assumption in second-label learning. Developmental Psychology, 30, 955-968.

Marler, P. (1970). A comparative approach to vocal learning: Song development in white-crowned sparrows. Journal of Comparative and Physiological Psychology, 71, 1-25.

Medina, L., \& Reiner, A. (2000). Do birds possess homologues of mammalian primary visual, somatosensory, and motor cortices? Trends in Neurosciences, 23, 1-12.

Pepperberg, I.M. (1999). The Alex studies. Cambridge, MA: Harvard University Press.

Pepperberg, I.M., Sandefer, R.M., Noel, D., \& Ellsworth, C.P. (2000). Vocal learning in the Grey Parrot (Psittacus erithacus): Effect of species identity and number of trainers. Journal of Comparative Psychology, 114, 371-380.

Pepperberg, I.M., \& Shive, H.A. (2001). Hierarchical combinations by a Grey Parrot (Psittacus erithacus): Bottle caps, lids, and labels. Journal of Comparative Psychology, 115, 376-384.

Pepperberg, I.M., \& Wilcox, S.E. (2000). Evidence for a form of mutual exclusivity during label acquisition by Grey parrots (Psittacus erithacus)? Journal of Comparative Psychology, 114, 219-231.

Rice, M.L., Huston, A.C., Truglio, R., \& Wright, J. (1990). Words from "Sesame Street": Learning vocabulary while viewing. Developmental Psychology, 26, 421-428.

Rozin, P. (1976). The evolution of intelligence and access to the cognitive unconscious. In J.M. Sprague \& A.N. Epstein (Eds.), Progress in psychobiology and physiological psychology (Vol. 6, pp. 245280). New York: Academic Press. 